Ruth Ann Marrie, MD,

$\mathrm{PhD}$

Lawrence Elliott, MD, MSc

James Marriott, MD, $\mathrm{MSc}$

Michael Cossoy, MD

James Blanchard, MD, $\mathrm{PhD}$

Stella Leung, MSc Nancy Yu, MD, PhD

Correspondence to

Dr. Marrie:

rmarrie@hsc.mb.ca
Supplemental data at Neurology.org

\section{Effect of comorbidity on mortality in multiple sclerosis OPEN}

\section{ABSTRACT}

Objective: We aimed to compare survival in the multiple sclerosis (MS) population with a matched cohort from the general population, and to evaluate the association of comorbidity with survival in both populations.

Methods: Using population-based administrative data, we identified 5,797 persons with MS and 28,807 controls matched on sex, year of birth, and region. We estimated annual mortality rates. Using Cox proportional hazards regression, we evaluated the association between comorbidity status and mortality, stratifying by birth cohort, and adjusting for sex, socioeconomic status, and region. We compared causes of death between populations.

Results: Median survival from birth in the MS population was 75.9 years vs 83.4 years in the matched population. MS was associated with a 2 -fold increased risk of death (adjusted hazard ratio 2.40; 95\% confidence interval: 2.24-2.58). Several comorbidities were associated with increased hazard of death in both populations, including diabetes, ischemic heart disease, depression, anxiety, and chronic lung disease. The magnitude of the associations of mortality with chronic lung disease, diabetes, hypertension, and ischemic heart disease was lower in the MS population than the matched population. The most common causes of death in the MS population were diseases of the nervous system and diseases of the circulatory system. Mortality rates due to infectious diseases and diseases of the respiratory system were higher in the MS population.

Conclusion: In the MS population, survival remained shorter than expected. Within the MS population, comorbidity was associated with increased mortality risk. However, comorbidity did not preferentially increase mortality risk in the MS population as compared with controls. Neurology ${ }^{\circledR} 2015 ; 85: 240-247$

\section{GLOSSARY}

$\mathbf{C I}=$ confidence interval; HR = hazard ratio; ICD-9 = International Classification of Diseases, Ninth Revision; ICD-9-CM = International Classification of Diseases, Ninth Revision, Clinical Modification; ICD-10-CA = International Classification of Diseases, Tenth Revision, Canada; IHD = ischemic heart disease; $\mathbf{M S}=$ multiple sclerosis; $\mathbf{R R}=$ relative risk

Multiple sclerosis (MS) affects more than 2.5 million persons worldwide. ${ }^{1,2}$ It is a disease with unexplained heterogeneity in outcomes, including survival. ${ }^{3}$ Some studies report that survival in MS has improved over the last 40 to 50 years. ${ }^{4-6}$ However, most studies suggest that survival remains lower than expected for an age- and sex-matched population without MS., ${ }^{4,7}$

The reasons for this survival disparity are incompletely understood, as are the relative contributions of disease-related complications and competing causes to mortality. Complications of MS, such as infection, have an important role. ${ }^{8}$ Causes unrelated to MS, such as cardiovascular disease, seem to contribute to the higher than expected mortality in other studies. ${ }^{4,9}$ However, the contribution of comorbidity to survival in MS has received little attention apart from one Finnish study focused on neurologic comorbidities. ${ }^{10}$

From the Departments of Internal Medicine (R.A.M., J.M., M.C.) and Community Health Sciences (R.A.M., L.E., J.B., S.L., N.Y.), University of Manitoba, Winnipeg; Epidemiology and Surveillance (N.Y.), Public Health and Primary Care Division, Manitoba Health, Winnipeg, Canada. Go to Neurology.org for full disclosures. Funding information and disclosures deemed relevant by the authors, if any, are provided at the end of the article. The Article Processing Charge was paid by an operating grant from the MS Society of Canada.

This is an open access article distributed under the terms of the Creative Commons Attribution-NonCommercial-NoDerivatives License 4.0 (CC BY-NC-ND), which permits downloading and sharing the work provided it is properly cited. The work cannot be changed in any way or used commercially. 
Using population-based administrative data, we aimed to compare changes in survival in the MS population with those in a matched cohort from the general population; evaluate the association of comorbidity with survival; and determine causes of death among persons with MS as compared with those in the matched cohort. We hypothesized that survival is improving in the MS population over time, and that survival is lower among persons with MS and comorbidity than among persons with MS without comorbidity.

METHODS Data sources. We used 2 data sources. The first was administrative (health) data from the province of Manitoba, Canada. A provincial health department, Manitoba Health, manages health services delivery to $98 \%$ of the province's 1.25 million residents. ${ }^{11}$ Manitoba Health maintains a population registry, which includes a unique personal health identification number for each insured individual, sex, dates of birth and death, and residential postal code. Migration in or out of the province is also recorded. Electronic records of all health services claims including hospitalizations, physician visits, and prescription claims are also maintained, and each one includes the unique personal health identification number identifying the person to whom the service was delivered.

The second data source was the Manitoba Vital Statistics Death Database held in the Population Data Repository at the Manitoba Centre for Health Policy. The database captures information on all deaths in Manitoba, including date and cause of death, and these data are provided to the Canadian Vital Statistics Death Database. ${ }^{12}$ Undercoverage in the Manitoba database may affect Manitobans who died outside of the province. Cause of death is classified using the ICD. From 1979 to 1999 , the death database used ICD-9 coding and one cause of death was available to investigators. Since 2000 , the death database has used $I C D-10-C A$ coding, and primary cause of death and up to 20 contributing causes of death were available to investigators. To protect confidentiality, data linkage was performed via scrambled personal health identification number using anonymized versions of these databases.

Standard protocol approvals, registrations, and patient consents. The University of Manitoba Health Research Ethics Board approved the study. The Manitoba Health Information Privacy Committee approved data access.

Study populations. Using a validated administrative case definition, ${ }^{13}$ we identified Manitobans with MS from April 1, 1984 (beginning of fiscal year 1984) to March 31, 2012 (end of fiscal year 2011). Cases of MS were defined as individuals with $\geq 3$ hospital, physician, or prescription claims for MS. Statistical efficiency is optimized at 4 to 6 matches, therefore we selected up to 5 controls for each MS case, matched on sex, exact year of birth, and region of residence (postal code) after excluding anyone with $\geq 1$ ICD-9-CM/ICD-10-CA diagnostic codes for any demyelinating disease. This ensured that we did not include anyone in the matched who might be classified as having MS in the future. For each person with MS, the date of the first claim for demyelinating disease (e.g., optic neuritis) was assigned as the index date and the same date was assigned to their matched controls.

Mortality. We used the population registry to identify the date of death. We report annual crude mortality rates per 1,000 person-years with $95 \%$ confidence intervals (CIs) overall, and age-specific rates. We also report rates standardized to the 2006 Canadian census population using the direct method. For the MS cohort, the possible causes of death were categorized as complications of MS, competing causes of death, suicide, or unclassifiable by 3 MS neurologists (for details, see e-Methods on the Neurology ${ }^{\circledR}$ Web site at Neurology.org).

Comorbidity. We chose comorbidities for study based on our prior work indicating they were associated with other outcomes in MS, or affected at least $5 \%$ of the MS population in Manitoba, ${ }^{14-16}$ and could be accurately identified using administrative case definitions although the degree of accuracy varied by condition. ${ }^{17-21}$ These included hypertension, diabetes, ischemic heart disease (IHD), chronic lung disease, autoimmune thyroid disease, epilepsy, migraine, depression, anxiety, and bipolar disorder. We applied validated administrative case definitions based on hospital, physician, and prescription claims for these comorbidities to both populations. ${ }^{17-21}$

Analyses. We estimated survival from birth and compared it between the 2 populations using univariate Cox regression with age as the time scale, because it is the strongest predictor of mortality. ${ }^{22}$ This model accounted for left truncation of the data using age at entry into the study (due to the availability of data from 1984 onward). ${ }^{23,24}$ Then, we constructed a multivariable Cox proportional hazards model to evaluate the association of MS with mortality as compared with the matched population. In a matched cohort design (where matching is on exposure), a matched analysis is not needed. ${ }^{25}$ Adjustment is not needed to control for confounding due to the matched variables if follow-up time is the same in both cohorts. If follow-up time is not the same because of differential survival, ${ }^{25}$ or nonmatched covariates are included in the analysis, ${ }^{26}$ then adjustment is needed. Therefore, covariates included sex, region (defined as urban for centers with populations of $\geq 50,000$ vs rural), and socioeconomic status in quintiles (as defined by linkage of postal code to census data). Socioeconomic status was updated every 10 years. To account for birth cohort effects, we stratified the model by birth year, grouped as 1890-1940, 1941-1969, and $\geq 1970$, based on the distribution of the study population. We repeated the analysis including MS as a time-varying covariate where the participant was considered exposed from the time of the first demyelinating disease claim; this accounted for the age at MS onset. We added comorbidities to the model as time-varying covariates in which the participant was considered exposed from the first claim for the comorbidity (see e-Methods). We conducted 2 sensitivity analyses: (1) restricting the analysis in the MS population to incident cases; and (2) including age at symptom onset as a stratifying variable, grouped as $<30,30$ 40 , and $\geq 40$ years.

For cause of death in the MS population, we summarized the frequency (percent) of deaths due to MS as coded on the death certificate, then the frequency (percent) of deaths due to complications of MS, competing causes, suicide, and unclassifiable as defined above. In both populations, we also classified cause of death according to $I C D-9$ chapters (which required mapping some deaths from $I C D-10$ to $I C D-9$ ), and report cause-specific mortality rates with $95 \%$ CI.

Sample size and power calculations are shown in e-Methods. Statistical analyses were conducted using SAS 9.2 (SAS Institute Inc., Cary, NC).

RESULTS We identified 5,797 persons with MS and 28,807 matched controls. The cohorts were well matched at the index date for age, sex, and region of residence (table 1). Anxiety, depression, epilepsy, 
Table 1 Characteristics of the MS population and the matched cohort from the general population

\begin{tabular}{|c|c|c|c|}
\hline Characteristic & $\begin{array}{l}\text { General population } \\
(n=28,807)\end{array}$ & $\begin{array}{l}\text { MS population } \\
(\mathrm{n}=5,797)\end{array}$ & p Value \\
\hline Female, n (\%) & $20,566(71.4)$ & $4,140(71.4)$ & 1.0 \\
\hline Age at index date, $y$, mean (SD) & $41.5(13.6)$ & $41.4(13.6)$ & 0.61 \\
\hline Duration of follow-up, $y$, mean (SD) & $55.6(15.6)$ & $55.4(14.9)$ & 0.37 \\
\hline Duration of follow-up from index date, $y$, mean (SD) & $13.6(8.6)$ & $13.4(12.4)$ & 0.14 \\
\hline Index year & & & 1.0 \\
\hline $1984-1989$ & $10,477(36.4)$ & $2,109(36.4)$ & \\
\hline $1990-1994$ & $5,163(17.9)$ & $1,040(17.9)$ & \\
\hline 1995-1999 & $3,888(13.5)$ & $782(13.5)$ & \\
\hline 2000-2004 & $4,322(15.0)$ & $872(15.0)$ & \\
\hline$\geq 2005$ & 4,957 (17.2) & 994 (17.2) & \\
\hline Urban region of residence at index date, $n(\%)$ & $16,840(58.5)$ & $3,423(59.0)$ & 0.41 \\
\hline Socioeconomic status at index date, $n$ (\%) & & & 1.0 \\
\hline Quintile 1 & $5,927(20.6)$ & $1,191(20.5)$ & \\
\hline Quintile 2 & 6,382 (22.2) & $1,283(22.1)$ & \\
\hline Quintile 3 & $5,014(17.4)$ & $1,010(17.4)$ & \\
\hline Quintile 4 & $5,754(20.0)$ & $1,158(20.0)$ & \\
\hline Quintile 5 & $5,730(19.9)$ & $1,155(19.9)$ & \\
\hline \multicolumn{4}{|l|}{ Comorbidity prevalence at index date, $\mathrm{n}(\%)$} \\
\hline Anxiety & 4,455 (15.5) & 1,289 (22.2) & $<0.0001$ \\
\hline Bipolar disorder & 427 (1.5) & $142(2.4)$ & $<0.0001$ \\
\hline Chronic lung disease & $1,898(6.6)$ & 480 (8.3) & $<0.0001$ \\
\hline Depression & $3,134(10.9)$ & $966(16.7)$ & $<0.0001$ \\
\hline Diabetes & 963 (3.3) & 179 (3.1) & 0.34 \\
\hline Epilepsy & $141(0.49)$ & $58(1.0)$ & $<0.0001$ \\
\hline Fibromyalgia & $400(1.4)$ & 216 (3.7) & $<0.0001$ \\
\hline Hypertension & $2,800(9.7)$ & $589(10.2)$ & 0.31 \\
\hline Ischemic heart disease & 628 (2.2) & $137(2.4)$ & 0.41 \\
\hline Migraine & $2,053(7.1)$ & $626(10.8)$ & $<0.0001$ \\
\hline Thyroid disease (autoimmune) & $713(2.5)$ & 169 (2.9) & 0.058 \\
\hline \multicolumn{4}{|l|}{ Comorbidity at study end, ${ }^{a} \mathrm{n}(\%)$} \\
\hline Anxiety & $10,512(36.5)$ & $2,628(45.3)$ & $<0.0001$ \\
\hline Bipolar disorder & $1,324(4.6)$ & $438(7.6)$ & $<0.0001$ \\
\hline Chronic lung disease & 5,266 (18.3) & $1,126(19.4)$ & 0.042 \\
\hline Depression & $7,993(27.7)$ & 2,407 (41.5) & $<0.0001$ \\
\hline Diabetes & $3,981(13.8)$ & 724 (12.5) & 0.0075 \\
\hline Epilepsy & $405(1.4)$ & $257(4.4)$ & $<0.0001$ \\
\hline Fibromyalgia & $1,352(4.7)$ & 648 (11.2) & $<0.0001$ \\
\hline Hypertension & $10,121(35.1)$ & $1,857(32.0)$ & $<0.0001$ \\
\hline Ischemic heart disease & 3,457 (12.0) & $682(11.8)$ & 0.63 \\
\hline Migraine & $5,532(19.2)$ & $1,568(27.0)$ & $<0.0001$ \\
\hline Thyroid disease (autoimmune) & $1,873(6.5)$ & $433(7.5)$ & 0.0076 \\
\hline
\end{tabular}

Abbreviation: MS = multiple sclerosis.

${ }^{a}$ End of study, death, or migration out of province, whichever came first. 
fibromyalgia, and migraine were more common in the MS population than in the matched population at the index date. The burden of comorbidity increased in both populations over the study period, indicating the need for time-varying covariates in our multivariable models.

Accounting for left truncation, the median survival from birth was 75.9 years in the MS population and 83.4 years in the matched population $(p<0.0001)$. This corresponded to a 2-fold unadjusted increased hazard of death in the MS population (hazard ratio [HR] 2.05; 95\% CI: 1.92-2.19). Survival was shortest in the earliest birth cohort for both populations, improving in more recent cohorts $(p<0.0001)$.

Mortality rates. As expected, mortality increased with age in both populations (table 2 shows findings in 2011). Over the entire study period, after adjusting for year, age-specific mortality was higher in the MS population than in the matched population. The relative risk (RR) of death in the MS population was greatest at younger ages, being about 3-fold higher at age 39 years and younger (RR 3.65; 95\% CI: 3.48-3.83) and ages 40 to 59 years (RR 2.88; 95\% CI: 2.81-2.95) but less than 2-fold higher at age 80 and older (RR 1.80; 95\% CI: 1.79-1.80).

We also observed a change in age-specific mortality rates over time, but this differed between the MS and matched populations. Considering all years of data, in the MS population, age-specific mortality did not change for persons aged 39 years and younger (0.0097; 95\% CI: $-0.083,0.10)$, but decreased by 0.23 (95\% CI: $-0.065,-0.39$ ) per 1,000 population per year for those aged 40 to 59 years and by 0.52 (95\% CI: $-0.25,-0.80$ ) for those aged 60 to 69 years. Declines in those aged 70 years and older were not statistically significant $(-2.21 ; 95 \% \mathrm{CI}:-4.94$, 0.52 ). In the matched population, age-specific mortality did not change for persons aged 39 years and younger but decreased by 0.11 (95\% CI: 0.04-0.18) per 1,000 persons per year for those aged 40 to 59 years, 0.41 (95\% CI: $0.20-0.63)$ for those aged 40 to
59 years, and 0.57 (95\% CI: 0.14-1.01) for those aged 60 to 79 years.

In a multivariable model adjusting for sex, socioeconomic status, and region of residence and stratified by birth year, the MS population had a 2.07 (95\% CI: 1.94-2.21) increased hazard of death (data not shown). When we included MS as a time-varying covariate to account for the age at MS onset (earlier onset would mean longer duration of exposure), the effect of MS on the risk of death increased (HR 2.40; 95\% CI: 2.25-2.57). When we added comorbidity to this model, the association of MS with mortality remained unchanged (HR 2.40; 95\% CI: 2.24-2.58) (table 3). Several comorbidities were independently associated with increased hazard of death, including diabetes, IHD, depression, anxiety, bipolar disorder, and chronic lung disease. Migraine and autoimmune thyroid disease were associated with a reduced hazard of death.

We identified an interaction between some of the comorbidities and study population; therefore, we constructed separate multivariable models for the 2 populations (table 3). The magnitude of the association of diabetes, hypertension, IHD, and chronic lung disease with mortality was greater in the matched population than in the MS population (all $p$ for interaction $<0.0001$ ). Bipolar disorder was associated with an increased hazard of death in the matched population but not in the MS population $(p=0.048)$, while autoimmune thyroid disease was associated with a reduced hazard of death in the matched population but not in the MS population $(p=0.26)$. Stratifying the model by age of MS onset did not change the findings (data not shown).

The characteristics of the individuals who died during the study period are shown in table e- 1 . The MS population had less total comorbidity than the matched population. Of the 1,257 people with MS who died over the entire study period, 433 (34.4\%; 95\% CI: $31.6 \%-36.7 \%$ ) had MS on their death certificates. For the period 1984 to 1999 when only one

Table 2 Age-specific mortality rates per 1,000 persons (95\% Cls) in the MS population and matched cohort from the general population in Manitoba in 2011

\begin{tabular}{|c|c|c|c|c|c|c|c|}
\hline \multirow[b]{2}{*}{ Age, y } & \multicolumn{3}{|c|}{ General population } & \multicolumn{3}{|c|}{ MS population } & \multirow[b]{2}{*}{ Rate ratio $(95 \% \mathrm{Cl})$} \\
\hline & $\begin{array}{l}\text { No. of } \\
\text { deaths }\end{array}$ & $\begin{array}{l}\text { Cohort size, } \\
\text { person-years }\end{array}$ & Rate $(95 \% \mathrm{Cl})$ & $\begin{array}{l}\text { No. of } \\
\text { deaths }\end{array}$ & $\begin{array}{l}\text { Cohort size, } \\
\text { person-years }\end{array}$ & Rate $(95 \% \mathrm{Cl})$ & \\
\hline$\leq 39$ & $\mathrm{~S}$ & S & $1.01(0.33,3.13)$ & $\mathrm{S}$ & $\mathrm{S}$ & $1.68(0.24,11.9)$ & $1.66(1.30,2.13)$ \\
\hline $40-59$ & 28 & $10,585.49$ & $2.64(1.83,3.83)$ & 12 & $2,083.5$ & $5.76(3.27,10.1)$ & $2.18(1.88,2.52)$ \\
\hline $60-69$ & 46 & $4,125.69$ & $11.1(0.84,14.9)$ & 16 & 767.93 & $20.8(12.8,34.0)$ & $1.87(1.74,2.01)$ \\
\hline $70-79$ & 44 & $1,885.2$ & $23.3(17.4,31.4)$ & 16 & 308.83 & $51.8(31.7,84.6)$ & $2.22(2.11,2.33)$ \\
\hline$\geq 80$ & 84 & 867.42 & $96.8(78.2,119.9)$ & 16 & 107.15 & $149.3(91.5,243.7)$ & $1.54(1.50,1.58)$ \\
\hline
\end{tabular}

Abbreviations: $\mathrm{Cl}$ = confidence interval; $\mathrm{MS}$ = multiple sclerosis; $\mathrm{S}=$ suppressed to preserve confidentiality. 


\begin{tabular}{|c|c|c|c|}
\hline \multicolumn{4}{|c|}{$\begin{array}{l}\text { Adjusted HRs }\left(95 \% \text { Cls) for the association of comorbidity }{ }^{a} \text { and mortality in the MS and matched }\right. \\
\text { populations }\end{array}$} \\
\hline Variable ${ }^{b}$ & Both populations & Matched population only & MS population only \\
\hline \multicolumn{4}{|l|}{ Population } \\
\hline Matched & 1.0 & & \\
\hline MS & $2.40(2.24,2.58)$ & & \\
\hline \multicolumn{4}{|l|}{ Sex } \\
\hline Female & 1.0 & 1.0 & 1.0 \\
\hline Male & $1.35(1.27,1.44)$ & $1.35(1.25,1.45)$ & $1.36(1.20,1.54)$ \\
\hline \multicolumn{4}{|l|}{ Region } \\
\hline Rural & 1.0 & 1.0 & 1.0 \\
\hline Urban & $1.13(1.05,1.22)$ & $1.05(0.97,1.15)$ & $1.38(1.19,1.61)$ \\
\hline \multicolumn{4}{|l|}{ Socioeconomic status } \\
\hline Quintile 1 & 1.0 & 1.0 & 1.0 \\
\hline Quintile 2 & $0.90(0.82,0.98)$ & $0.95(0.85,1.05)$ & $0.76(0.64,0.91)$ \\
\hline Quintile 3 & $0.90(0.82,0.99)$ & $1.01(0.90,1.14)$ & $0.71(0.58,0.86)$ \\
\hline Quintile 4 & $0.81(0.73,0.90)$ & $0.91(0.81,1.02)$ & $0.62(0.51,0.75)$ \\
\hline Quintile 5 & $0.75(0.68,0.84)$ & $0.84(0.74,0.95)$ & $0.59(0.48,0.73)$ \\
\hline \multicolumn{4}{|l|}{ Comorbidity } \\
\hline Diabetes & $1.60(1.48,1.72)$ & $1.66(1.53,1.80)$ & $1.47(1.25,1.73)$ \\
\hline Hypertension & $1.08(1.01,1.15)$ & $1.11(1.03,1.20)$ & $0.92(0.80,1.05)$ \\
\hline Ischemic heart disease & $1.80(1.68,1.93)$ & $1.87(1.73,2.03)$ & $1.50(1.28,1.75)$ \\
\hline Depression & $1.52(1.40,1.65)$ & $1.52(1.37,1.67)$ & $1.62(1.39,1.88)$ \\
\hline Anxiety & $0.77(0.71,0.84)$ & $0.79(0.72,0.87)$ & $0.72(0.61,0.84)$ \\
\hline Bipolar & $1.44(1.24,1.67)$ & $1.56(1.31,1.86)$ & $1.10(0.83,1.47)$ \\
\hline Autoimmune thyroid disease & $0.87(0.76,0.99)$ & $0.83(0.71,0.97)$ & $1.01(0.77,1.33)$ \\
\hline Migraine & $0.68(0.60,0.77)$ & $0.71(0.61,0.82)$ & $0.61(0.48,0.76)$ \\
\hline Epilepsy & $1.32(0.55,3.17)$ & $1.25(0.40,3.90)$ & $1.07(0.27,4.31)$ \\
\hline Lung disease & $1.60(1.50,1.72)$ & $1.73(1.60,1.87)$ & $1.21(1.03,1.42)$ \\
\hline
\end{tabular}

Abbreviations: $\mathrm{Cl}=$ confidence interval; $\mathrm{HR}=$ hazard ratio; $\mathrm{MS}=$ multiple sclerosis.

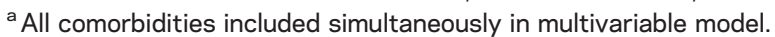

${ }^{\mathrm{b}}$ Age as time scale, stratified by birth cohort, population, socioeconomic status, and comorbidity, all time-varying.

cause of death was available, there were 559 deaths. Of these, 185 (33.1\%; 95\% CI: 29.3\%-37.2\%) had MS on their death certificate; cause of death was missing for 9 individuals. In the period 2000 to 2011, there were 690 deaths. Considering the primary cause of death, 248 (35.9\%; 95\% CI: 31.8\%-38.7\%) had MS on their death certificate. When underlying cause of death and the primary cause of death were both considered, 373 (54.1\%; 95\% CI: 48.4\%-55.7\%) had MS on their death certificate.

After consensus reclassification of cause of death in the MS population, competing causes were more common than MS or MS complications during the entire study period $(p=0.0004)$, as well as from 1984 to 1999 and from 2000 to 2011 (table e-2). There was a slight shift to more deaths being due to a competing cause in the second time period. Deaths due to MS occurred at younger ages than deaths due to competing causes (table e-3).

When we classified the cause of death by ICD-9 chapter, the most common cause of death in the MS population was diseases of the nervous system (that is, MS or other neurologic disorders), followed by diseases of the circulatory system, neoplasms, and diseases of the respiratory system (tables e-4 and e-5). These accounted for $82.8 \%$ of deaths. Mortality rates due to neoplasms were lower in the MS population than in the matched population. Mortality rates due to infectious diseases and diseases of the respiratory system were higher in the MS population than in the matched population.

DISCUSSION We used a population-based dataset with extended follow-up to address potential biases 
related to inclusion of hospital or clinic-based populations, small numbers of deaths and inadequate power, and immortal time bias. ${ }^{27,28} \mathrm{We}$ found that survival improved over time in the MS population but remained lower than in a matched population without MS. Comorbidity was associated with increased mortality but did not confer a greater risk of mortality in the MS population than in the matched population.

Previously we showed a shift in the peak agespecific prevalence of MS in Manitoba to older ages, ${ }^{13}$ suggesting that patients with MS are living longer. Consistent with those findings, we observed herein that the age at death in the MS population increased over time, and age-specific mortality rates decreased in persons aged 40 to 69 years. In Denmark and Australia, survival has also improved in MS but a survival disadvantage persists. ${ }^{4,6}$

Several comorbidities were associated with altered mortality risks in both populations. Mortality risk was higher among depressed individuals but lower among anxious individuals. In chronic disease populations such as those with diabetes or rheumatoid arthritis, depression is consistently associated with increased mortality independent of disease activity. ${ }^{29,30}$ Prior findings regarding the association of anxiety and mortality in other populations have conflicted, possibly because of the failure to control for other comorbidities, but a recent, large population-based study found that anxiety was associated with lower all-cause and cardiovascular mortality. ${ }^{31}$ One postulated reason for these findings is that depression is associated with less help-seeking behavior while anxiety is associated with more help-seeking. ${ }^{32}$ Bipolar disorder was not associated with mortality in the MS population possibly because of a smaller sample size.

The association of diabetes, hypertension, and IHD, and particularly chronic lung disease with mortality was lower in the MS population than in the matched population. Autoimmune thyroid disease was not associated with mortality in the MS population, but was associated with reduced mortality in the matched population. We previously found that the presence of any comorbidity conferred a lower risk of hospitalization in the MS population than in the matched population. ${ }^{33}$ Possible reasons for such disparities include greater ascertainment of (possibly milder) comorbidity because of greater health care utilization in the MS population, or better care of comorbidity in the MS population. ${ }^{34}$ The reasons for the protective effect of thyroid disease in the matched population are uncertain. Possibly, the requirement for ongoing care and repeated health care contacts leads to improvements in other aspects of health care. Unmeasured confounders may also be responsible.
One prior study evaluated the association of comorbidity with mortality in 490 persons with MS, focusing on migraine, epilepsy, and stroke. ${ }^{10}$ Only stroke was associated with increased mortality. However, migraine was more common in women with a "benign" MS course, which could be consistent with our finding that migraine was associated with reduced mortality. We lacked clinical data to further investigate this possibility. Epilepsy was not associated with mortality in our study or the prior study.

The sensitivity of death certificates for the diagnosis of MS was relatively low at 34\%. While this improved after 2000 when underlying cause of death was also available, the sensitivity of death certificates improved to only $54 \%$. Work in other jurisdictions has also shown that death certificates have a variable sensitivity for MS ranging from 46\% to $83 \%$ highlighting the potential for bias if mortality studies focus only on identifying the MS population using death certificates. ${ }^{35-37}$ Thus, an important aspect of our work was identifying the MS population using other sources.

We found that $44 \%$ of patients with MS were reported to have died of MS and related complications, and this changed relatively little over the study period. Apart from MS, the most common causes of death were circulatory system disease, cancer, and respiratory disease, similar to prior reports in Denmark. ${ }^{4}$ Deaths due to infection and respiratory disease were higher than expected, similar to reports in the United States. ${ }^{8}$ MS-related mortality in our population was lower than that reported in prior studies in which $47 \%$ to $75 \%$ of patients with MS died secondary to disease complications, ${ }^{38,39}$ such as urinary tract infections, pressure ulcers, and pneumonia. ${ }^{40}$

Since we had access to data from 1984 onward, some individuals with MS may have died before they could be captured but we accounted for this left truncation in our regression models. We lacked details regarding disability and clinical course but a recent review noted the absence of an effect of disease course on survival from birth in MS. ${ }^{3}$ We assessed the effect of comorbidities on survival, unlike most prior studies. Although relevant, we did not evaluate the effect of disease-modifying therapy on mortality because this would have required a different study design. This study had several strengths. We used validated algorithms to identify the entire MS population in our region and to identify comorbidities. We also had a long duration of follow-up.

Survival is improving in the MS population but remains a median of 7 years lower than in a population matched for age, sex, and socioeconomic status. At least $50 \%$ of deaths in the MS population are due to competing causes. Several comorbidities are 
associated with an increased risk of death in MS: depression, diabetes, and IHD conferred the greatest increases in risk. Although comorbidity did not have greater effect on mortality in the MS population than in the matched population, optimizing the management of comorbidity may be a means of improving survival.

\section{AUTHOR CONTRIBUTIONS}

The corresponding author (R.A.M.) and analyst (S.L.) had access to all the data in the study and take responsibility for the integrity of the data and the accuracy of the data analysis. Ruth Ann Marrie, Nancy Yu, Lawrence Elliott, and James Blanchard designed the study and obtained funding. Ruth Ann Marrie and Stella Leung analyzed the data. Ruth Ann Marrie drafted the manuscript. All authors revised the manuscript and approved the final version to be published.

\section{STUDY FUNDING}

This study was supported (in part) by operating grants and a Don Paty Career Development Award from the MS Society of Canada and a Manitoba Research Chair from Research Manitoba. The funding source(s) had no role in the study design, collection, analysis, or interpretation of the data or in the decision to submit the article for publication. The results and conclusions presented are those of the authors. No official endorsement by Manitoba Health or the Vital Statistics Agency is intended or should be inferred.

\section{DISCLOSURE}

R.A. Marrie receives research funding from Canadian Institutes of Health Research, Public Health Agency of Canada, Manitoba Health Research Council, Health Sciences Centre Foundation, Multiple Sclerosis Society of Canada, Multiple Sclerosis Scientific Foundation, Rx\&D Health Research Foundation, and has conducted clinical trials funded by Sanofi-Aventis. L. Elliott receives research support from the Canadian Institutes of Health Research, Public Health Agency of Canada, and the Multiple Sclerosis Society of Canada. J. Marriott received research support for MS trials from Biogen Idec, Roche, and Sanofi-Aventis and honoraria from Biogen Idec, Roche, and EMD Serono. He has received research support from the Consortium of MS Centers and the Manitoba Medical Service Foundation. M. Cossoy has received an honorarium for educational activities from EMD Serono. J. Blanchard receives research support from the Multiple Sclerosis Society of Canada, CIHR, Bill \& Melinda Gates Foundation, Canadian International Development Agency, and the United States Agency for International Development. S. Leung reports no disclosures relevant to the manuscript. N. Yu receives research support from the Canadian International Development Agency, the Multiple Sclerosis Society of Canada, CIHR, and Manitoba Health. Go to Neurology.org for full disclosures.

Received November 7, 2014. Accepted in final form March 19, 2015.

\section{REFERENCES}

1. Dean G. How many people in the world have multiple sclerosis? Neuroepidemiology 1994;13:1-7.

2. Beck CA, Metz LM, Svenson LW, Patten SB. Regional variation of multiple sclerosis prevalence in Canada. Mult Scler 2005;11:516-519.

3. Scalfari A, Knappertz V, Cutter G, Goodin DS, Ashton R, Ebers GC. Mortality in patients with multiple sclerosis. Neurology 2013;81:184-192.

4. Bronnum-Hansen H, Koch-Henriksen N, Stenager E. Trends in survival and cause of death in Danish patients with multiple sclerosis. Brain 2004;127:844-850.

5. Llorca J, Guerrero-Alonso P, Prieto-Salceda D. Mortality trends of multiple sclerosis in Spain, 1951-1997: an ageperiod-cohort analysis. Neuroepidemiology 2005;24:129-134.
6. Ekestern E, Lebhert G. Mortality from multiple sclerosis in Austria 1970-2001: dynamics, trends, and prospects. Eur J Neurol 2004;11:511-520.

7. Sadovnick AD, Ebers GC, Wilson RW, Paty DW. Life expectancy in patients attending multiple sclerosis clinics. Neurology 1992;42:991-994.

8. Goodin DS, Corwin M, Kaufman D, et al. Causes of death among commercially insured multiple sclerosis patients in the United States. PLoS One 2014;9:e105207.

9. Lalmohamed A, Bazelier MT, Van Staa TP, et al. Causes of death in patients with multiple sclerosis and matched referent subjects: a population-based cohort study. Eur J Neurol 2012;19:1007-1014.

10. Krokki O, Bloigu R, Ansakorpi H, Reunanen M, Remes AM. Neurological comorbidity and survival in multiple sclerosis. Mult Scler Relat Disord 2014;3:72-77.

11. Health Information Management Branch. Population Report. Winnipeg: Manitoba Health and Healthy Living; 2008.

12. Statistics Canada. Vital Statistics Death Database [online]. Available at: http://www.statcan.gc.ca/cgi-bin/imdb/p2SV.pl? Function $=$ getSurvey $\&$ SDDS $=3233 \&$ lang $=\mathrm{en} \& \mathrm{db}=\mathrm{im}$ $\mathrm{db} \& \mathrm{adm}=8 \& \mathrm{dis}=2$. Accessed March 6, 2011.

13. Marrie RA, Yu N, Blanchard JF, Leung S, Elliott L. The rising prevalence and changing age distribution of multiple sclerosis in Manitoba. Neurology 2010;74:465-471.

14. Marrie RA, Horwitz RI, Cutter G, Tyry T, Campagnolo D, Vollmer T. Comorbidity delays diagnosis and increases disability at diagnosis in MS. Neurology 2009;72:117-124.

15. Dallmeijer AJ, Beckerman $\mathrm{H}$, de Groot $\mathrm{V}$, van de Port IGL, Lankhorst GJ, Dekker J. Long-term effect of comorbidity on the course of physical functioning in patients after stroke and with multiple sclerosis. J Rehabil Med 2009;41:322-326.

16. Warren SA, Turpin KV, Pohar SL, Jones CA, Warren KG. Comorbidity and health-related quality of life in people with multiple sclerosis. Int J MS Care 2009;11:6-16.

17. Marrie RA, Yu B, Leung $S$, et al. Rising prevalence of vascular comorbidities in MS: validation of administrative definitions for diabetes, hypertension, hyperlipidemia. Mult Scler 2012;18:1310-1319.

18. Marrie RA, Yu BN, Leung $S$, et al. The utility of administrative data for surveillance of comorbidity in multiple sclerosis: a validation study. Neuroepidemiology 2013;40:85-92.

19. Marrie RA, Fisk JD, Yu BN, et al. Mental comorbidity and multiple sclerosis: validating administrative data to support population-based surveillance. BMC Neurol 2013;13:16

20. Marrie RA, Yu BN, Leung S, et al. Prevalence and incidence of ischemic heart disease in multiple sclerosis: a population-based validation study. Mult Scler Relat Disord 2013;2:355-361.

21. Marrie RA, Yu BN, Leung $S$, et al. The incidence and prevalence of fibromyalgia are higher in multiple sclerosis than the general population: a population-based study. Mult Scler Relat Disord 2012;1:162-167.

22. Lamarca R, Alonso J, Gómez G, Muñoz Á. Left-truncated data with age as time scale: an alternative for survival analysis in the elderly population. J Gerontol A Biol Sci Med Sci 1998;53:M337-M343.

23. Gross S, Lai T. Nonparametric estimation and regression analysis with left-truncated and right-censored data. J Am Stat Assoc 1996;91:1166-1180. 
24. Allison PD. Survival Analysis Using SAS: A Practical Guide. Cary, NC: SAS Press; 1995.

25. Rothman KJ, Greenland S, editors. Modern Epidemiology, 2nd ed. Philadelphia: Lippincott Williams \& Wilkins; 1998.

26. Sjölander A, Greenland S. Ignoring the matching variables in cohort studies: when is it valid and why? Stat Med 2013;32:4696-4708.

27. Ford HL, Gerry E, Johnson M, Williams R. A prospective study of the incidence, prevalence and mortality of multiple sclerosis in Leeds. J Neurol 2002;249: 260-265.

28. Patzold U, Pocklington PR. Course of multiple sclerosis: first results of a prospective study carried out of $102 \mathrm{MS}$ patients from 1976-1980. Acta Neurol Scand 1982;65: 248-266.

29. Ang DC, Choi H, Kroenke K, Wolfe F. Comorbid depression is an independent risk factor for mortality in patients with rheumatoid arthritis. J Rheumatol 2005;32: 1013-1019

30. van Dooren FE, Nefs G, Schram MT, Verhey FR, Denollet J, Pouwer F. Depression and risk of mortality in people with diabetes mellitus: a systematic review and meta-analysis. PLoS One 2013;8:e57058.

31. Mykletun A, Bjerkeset O, Dewey M, Prince M, Overland S, Stewart R. Anxiety, depression, and causespecific mortality: the HUNT Study. Psychosom Med 2007;69:323-331.
32. Roness A, Mykletun A, Dahl AA. Help-seeking behaviour in patients with anxiety disorder and depression. Acta Psychiatr Scand 2005;111:51-58.

33. Marrie RA, Elliott L, Marriott J, Cossoy M, Tennakoon A, Yu N. Comorbidity increases the risk of hospitalizations in multiple sclerosis. Neurology 2015;84:350-358.

34. Higashi T, Wenger NS, Adams JL, et al. Relationship between number of medical conditions and quality of care. N Engl J Med 2007;356:2496-2504.

35. Larsen JP, Kvale G, Aarli JA. Multiple sclerosis and mortality statistics. Acta Neurol Scand 1985;71:237-241.

36. O'Malley F, Dean G, Elian M. Multiple sclerosis and motor neurone disease: survival and how certified after death. J Epidemiol Community Health 1987;41:14-17.

37. Ragonese P, Salemi G, Aridon P, et al. Accuracy of death certificates for motor neuron disease and multiple sclerosis in the province of Palermo in southern Italy. Neuroepidemiology 2002;21:148-152.

38. Riudavets MA, Colegial C, Rubio A, Fowler D, Pardo C, Troncoso JC. Causes of unexpected death in patients with multiple sclerosis: a forensic study of 50 cases. Am J Forensic Med Pathol 2005;26:244-249.

39. Sadovnick AD, Eisen K, Ebers GC, Paty DW. Cause of death in patients attending multiple sclerosis clinics. Neurology 1991;41:1193-1196.

40. Redelings MD, McCoy L, Sorvillo F. Multiple sclerosis mortality and patterns of comorbidity in the United States from 1990 to 2001. Neuroepidemiology 2006;26:102-107.

\section{This Week's Neurology ${ }^{\circledR}$ Podcast}

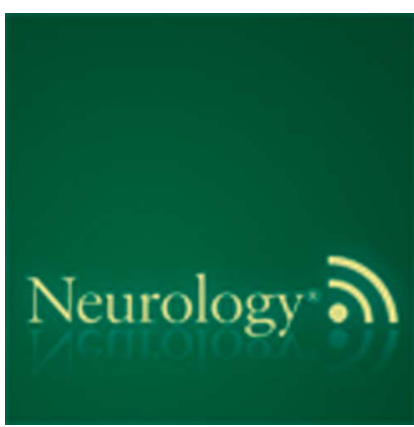

Paraneoplastic neurologic disorders in small cell lung carcinoma: A prospective study (see p. 235)

This podcast begins and closes with Dr. Robert Gross, Editor-inChief, briefly discussing highlighted articles from the July 21, 2015, issue of Neurology. In the second segment, Dr. Elliot Dimberg talks with Dr. Paul Gozzard about his paper on paraneoplastic neurologic disorders in small cell lung carcinoma. Dr. Sarah Wesley reads the e-Pearl of the week about Bálint syndrome. In the next part of the podcast, Dr. Alberto Espay focuses his interview with Dr. Lloyd Kasper on his Hot Topic Lecture at the AAN Annual Meeting on the topic of digesting the gut microbiome: role in CNS demyelinating disease.

Disclosures can be found at Neurology.org.

At Neurology.org, click on "RSS" in the Neurology Podcast box to listen to the most recent podcast and subscribe to the RSS feed.

CME Opportunity: Listen to this week's Neurology Podcast and earn 0.5 AMA PRA Category 1 CME Credits ${ }^{\mathrm{TM}}$ by answering the multiple-choice questions in the online Podcast quiz. 


\section{Neurology}

Effect of comorbidity on mortality in multiple sclerosis

Ruth Ann Marrie, Lawrence Elliott, James Marriott, et al.

Neurology 2015;85;240-247 Published Online before print May 27, 2015

DOI 10.1212/WNL.0000000000001718

This information is current as of May 27, 2015

\section{Updated Information \& \\ Services}

Supplementary Material

\section{References}

Citations

Subspecialty Collections

Permissions \& Licensing

Reprints including high resolution figures, can be found at:

http://n.neurology.org/content/85/3/240.full

Supplementary material can be found at:

http://n.neurology.org/content/suppl/2015/05/27/WNL.0000000000001 718.DC1

This article cites 36 articles, 8 of which you can access for free at: http://n.neurology.org/content/85/3/240.full\#ref-list-1

This article has been cited by 15 HighWire-hosted articles: http://n.neurology.org/content/85/3/240.full\#\#otherarticles

This article, along with others on similar topics, appears in the following collection(s):

All epidemiology

http://n.neurology.org/cgi/collection/all_epidemiology

Multiple sclerosis

http://n.neurology.org/cgi/collection/multiple_sclerosis

Information about reproducing this article in parts (figures,tables) or in its entirety can be found online at:

http://www.neurology.org/about/about_the_journal\#permissions

Information about ordering reprints can be found online:

http://n.neurology.org/subscribers/advertise

Neurology ${ }^{\circledR}$ is the official journal of the American Academy of Neurology. Published continuously since 1951, it is now a weekly with 48 issues per year. Copyright @ 2015 American Academy of Neurology. All rights reserved. Print ISSN: 0028-3878. Online ISSN: 1526-632X.

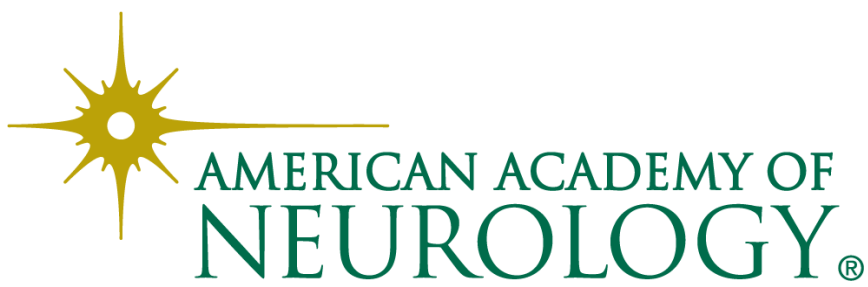

